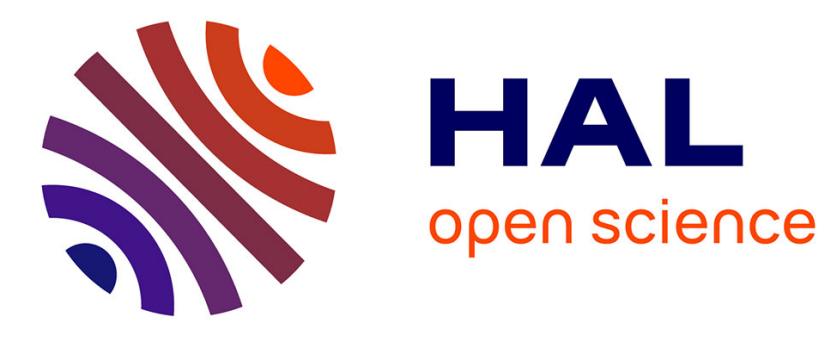

\title{
Hand Hygiene Analyzed by Video Recording
}

Sophia Boudjema, Pauline Reynier, Jean-Charles Dufour, Olga Florea,

Philippe Patouraux, Patrick Peretti-Watel, Philippe Brouqui

\section{To cite this version:}

Sophia Boudjema, Pauline Reynier, Jean-Charles Dufour, Olga Florea, Philippe Patouraux, et al.. Hand Hygiene Analyzed by Video Recording. Journal of Nursing \& Care, 2016, 05 (02), pp.1000338. 10.4172/2167-1168.1000338 . hal-03085840

\section{HAL Id: hal-03085840 https://hal.science/hal-03085840}

Submitted on 29 Dec 2020

HAL is a multi-disciplinary open access archive for the deposit and dissemination of scientific research documents, whether they are published or not. The documents may come from teaching and research institutions in France or abroad, or from public or private research centers.
L'archive ouverte pluridisciplinaire HAL, est destinée au dépôt et à la diffusion de documents scientifiques de niveau recherche, publiés ou non, émanant des établissements d'enseignement et de recherche français ou étrangers, des laboratoires publics ou privés. 


\title{
Hand Hygiene Analyzed by Video Recording
}

Sophia Boudjema ${ }^{1,2 \#}$, Pauline Reynier ${ }^{3 \#}$, Jean Charles Dufour ${ }^{3,4 \#}$, Olga Florea ${ }^{2 \#}$, Philippe Patouraux ${ }^{3}$, Patrick Peretti-Watel Pand $^{3,5 \#}$ Philippe Brouqui ${ }^{1,2 \# *}$

${ }^{1}$ Aix Marseille Université, URMITE, UM63, CNRS 7278, IRD 198, Inserm 1095, Marseille, France

2 Infectious Disease Unit CHU Nord, Assistance Publique des Hôpitaux de Marseille, France

${ }^{3}$ Aix Marseille University, UMR912 SESSTIM (AMU-Inserm-IRD-AMSE), Marseille, France

${ }^{4}$ BIOSTIC, Pôle de Santé Publique, Assistance Publique des Hôpitaux de Marseille,

${ }^{5}$ ORS PACA, Southeastern Health Regional Observatory, 13006, Marseille, France

\#Institut Hospitalo Universitaire IHU Méditerranée Infection

\begin{abstract}
Objective : The aim of this study is to evaluate the hand hygiene and isolation precaution adhesion of the healthcare workers in routine cares.

Methods : In an infectious diseases care unit of a university hospital in Marseille, France, we designed an observational study at evaluating the hand hygiene and isolation precaution adhesion of the healthcare workers in routine cares by remote video recording. The care team including nurses, assistant nurses, housekeepers and physicians was monitored from November $30^{\text {th }}(2012)$ to February $13^{\text {th }}(2013)$. From a video camera was placed inside patient room, healthcare workers paths were recorded from entrance to exit of the patient's room. Hand hygiene disinfection as well as gloves and mask wearing in isolation precautions were observed. A video camera was placed inside patient room. Healthcare workers paths were recorded from entrance to exit of the patient's room. A nurse and a sociologist analyzed further videos. Hand hygiene disinfection as well as gloves and mask wearing in isolation precaution were observed.

Results : A total of 756 videos were captures. 249 were rejected because they were not contributive and 507 videos (811 Healthcare workers paths) were analyzed. Healthcare workers had hand disinfection at least one time in the path in $28.2 \%$. Hand disinfection at entrance and exit of the bedroom is respected in $6.2 \%$. The meal tray delivery is associated with a lower hand hygiene practice. The glove wearing adhesion is $51.2 \%$ in Clostridium difficile contact precaution, and conformity to protocol is $17.5 \%$. Wearing gloves impairs hand disinfection especially in situation where gloves are not part of the protocol (38.7\%). Adhesion to mask wearing in airborne precaution is $90.7 \%$.
\end{abstract}

Keywords: Video; Hand hygiene; Healthcare worker; Behavior; Healthcare practices; Isolation precautions

\section{Introduction}

Hand hygiene practice has been proven to be efficient to limit the spread of infectious diseases in hospital setting [1]. Measurement of hand hygiene compliance is an important component of infection control programs [2,3]. The World Health Organization (WHO) recommends regular monitoring to improve the hand hygiene compliance. Currently, most healthcare facilities measure hand hygiene compliance almost exclusively via direct human observation of healthcare workers $[4,5]$. While considered as the "gold standard" [6], direct observation is laborintensive and susceptible to observer biases [6-8]. The observation bias has been investigates and proven to influence the behavior of the observed person [9]. Furthermore, the reliability of directly observed hand hygiene audits as a reflection of overall performance can be adversely affected by sporadic or inconsistent sampling [6]. Using such monitoring method, the compliance of hand hygiene is varying from $4-100 \%$ [4]. Despite many interventions, hand hygiene practices remain very poorly followed in most hospitals. One should investigate conditions during care that could explain this poor adhesion. Video recording is commonly used in sport coaching to analyze and improve practices $[9,10]$. Video recording has also been used in health care to explain the falls of elderly [11] and to allow corrective measures. To our knowledge only one study already use remote video analysis of hand hygiene in intensive care unit (ICU), with feedback to the health Care Workers (HCWs) showing a significant improvement $[12,13]$. We decided to use video recording to investigate the HCWs practices during time of care and identify conditions that would explain poor hand hygiene compliance and non-adhesion to isolation precaution protocols $[14,15]$.

\section{Method}

We studied the hand hygiene practices all along the HCW pathway during time of care. The HCWs were identified according to their professional category, sex and educational level. We extracted from videotapes information regarding hand hygiene practice, its interference with meal tray delivery, housekeeping, the mask and gloves wearing. Repeated situations were characterized and classified for further statistical analysis. Furthermore, as hand hygiene depends upon patient's isolation procedure we notified when room was in Clostridium difficile isolation, airborne, or contact isolation procedures [16].

As for glove wearing we notified the wearing and the conformity to protocols. In standard, and airborne precaution situations, we defined that wearing gloves is conformed when gloves were put on within the room and removed before exit from the room. In Clostridium difficile isolation wearing gloves is conformed when gloves were worn before enter into the room and removed before exit from the room. Finally we studied the hand hygiene practices depending on the type of care. For doing this we define three care situations: Non-invasive care (medical examination, temperature, blood pressure, and treatment delivery), Invasive care (blood puncture, blood sampling, catheterization, blood transfusion) and nursing including bandage, urines and tools collection. The observation took place in an infectious diseases service of the University Hospital in Marseille France. All HCWs working

*Corresponding author: Philippe Brouqui, Institut Hospitalo-Universitaire Méditerranée Infection, 13005 Marseille, France, Tel: +334 913855 17; E-mail: philippe.brouqui@univ-amu.fr

Received March 11, 2016; Accepted March 29, 2016; Published April 06, 2016

Citation: Brouqui P, Boudjema S, Reynier P, Dufour JC, Florea O, et al. (2016) Hand Hygiene Analyzed by Video Recording. J Nurs Care 5: 338. doi:10.4172/21671168.1000338

Copyright: $\odot 2016$ Brouqui $P$, et al. This is an open-access article distributed under the terms of the Creative Commons Attribution License, which permits unrestricted use, distribution, and reproduction in any medium, provided the original author and source are credited. 


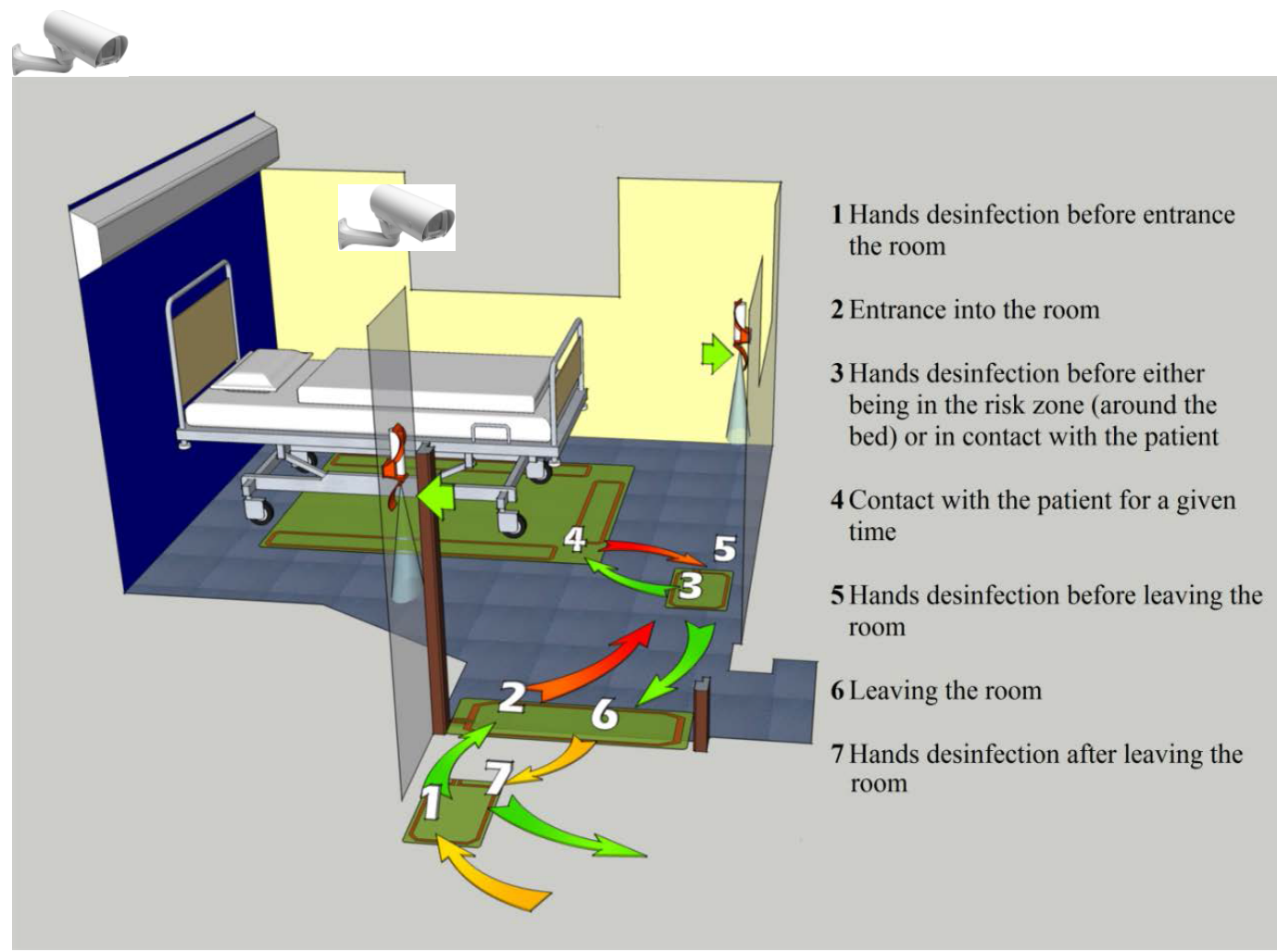

Figure 1: Schema of the experimental room with video camera and antennas from MédiHandTrace ${ }^{\circledR}$.

there were asked to participate, including nurses, students, assistant nurses, housekeepers and physicians. A video camera was installed in one room of the ward, specially equipped with a continuous automated hand hygiene monitor MediHandTrace (r) [17] (Medihandtrace SAS BP 70351, 83077 Toulon cedex 9 France) as shown in Figure 1. The video camera was installed in such a way that only HCWs and not patient were recorded. The video camera was automatically started once a HCW enters into the room and stops five seconds after (s) he exits from the room as determined by MediHandTrace. All video recording were detained on the MediHandTrace server [17]. Videos were further analyzed by a nurse (SB) and a sociologist (PP).

When needed, variables were compared by using exact Fisher test or $\mathrm{Chi}^{2}$. A significant different was established when $\mathrm{p}$ value $<0.05$. In order to ensure anonymity of the data analyzed, a random number was attributed to each participant when captured in the database. Two experts did this analyze. The first was a nurse from the team care and the second was a sociologist. Only the experts knew the HCWs names and faces. In the videotape presented here, faces were hidden in order to preserve anonymity. In all case, an oral and written consent was obtained from the HCWs. We systematically asked agreement of the patient. If the patient refused (s) he was displaced to another bedroom. This ethic statement was declared to the French Commission on Individual Data Protection and Public Liberties (CNIL).

\section{Results}

In this study, 756 videos were captures from November $30^{\text {th }}(2012)$ to February $13^{\text {th }}(2013) .507$ videos were analyzed and 249 rejected because the health care worker path was not completely recorded on the video. The 507 videotapes identified $1123 \mathrm{HCW}$ paths. Of them 811 were analyzed, $312 \mathrm{HCW}$ paths were rejected because there were no
Use of hydro-alcoholic solution in the patient's room:

At both entrance and exit

Only at entrance

$70(8.6 \%)$

Only at exit

$21(2.6 \%)$

At entrance (missing data for exit)

At exit (missing data for entrance)

$72(8.9 \%)$

At least one time during the $\mathrm{HCW}$ path (either entrance or exit) Never

$14(1.7 \%)$

$52(6.4 \%)$

$229(28.2 \%)$

$582(71.8 \%)$

Total

811

Table 1: Hand disinfection among HCWs in hospital setting ( $\mathrm{N}=811$ paths, France 2013-2014).

visible information about the use of the hydro alcoholic solution.

Among $75 \mathrm{HCWs}$, asked to participate all accepted but 13 were further excluded from this analysis with the rejected videos (see above). Finally of 62 HCWs participate, 14 were nurses, 6 assistant nurses, 4 housekeepers, 28 medical students and 10 medical doctors.

Overall, of the 811 observed paths in the patient' room, HCWs had hand disinfection at least one time in 229 (28.2\%) of path (Table 1). HCWs had hand disinfection both at entrance and exit of their path in $70 / 811(8.6 \%)$ and at entrance only in $21 / 811(2.6 \%)$ of path. Hand disinfection adhesion was significantly different between HCWs categories ( $p$ value $<0.0001)$. We observed that hand disinfection was the highest for medical doctors, then for medical students, then for nurses, then for housekeepers and finally for nurses assistant (Table 2). When the HCWs get into the bedroom with a meal tray, adhesion to hand disinfection is observed in 12/95 (12.6\%) which is significantly lower than when the HCWs get in the room without meal tray $217 / 716(30.3 \%) p=0.0003$ (Table 2). This could be illustrated in many videos: typically, the assistant nurse entered into the room 
Citation: Brouqui P, Boudjema S, Reynier P, Dufour JC, Florea O, et al. (2016) Hand Hygiene Analyzed by Video Recording. J Nurs Care 5: 338. doi:10.4172/2167-1168.1000338

Page 3 of 5

\begin{tabular}{|c|c|c|c|c|c|}
\hline & $p^{*}$ & Number of HCWs & At least one time $\mathrm{N}=229(28.2 \%)$ & Never $\mathrm{N}=582(71.8 \%)$ & Total $(\mathrm{N}=811)$ \\
\hline & & & $\mathrm{N}$ (\% row) & $\mathrm{N}$ (\% row) & $\mathrm{N}(\%$ column $)$ \\
\hline HCW Categories & $<0.0001$ & & & & \\
\hline nurse & & 14 & $107(37.8 \%)$ & $176(62.2 \%)$ & $283(34.9 \%)$ \\
\hline nurse assistant & & 6 & $6(2.9 \%)$ & $203(97.1 \%)$ & $209(25.8 \%)$ \\
\hline housekeepers & & 4 & $22(15.8 \%)$ & $117(84.2 \%)$ & $139(17.1 \%)$ \\
\hline medical students & & 28 & $72(49.7 \%)$ & $73(50.3 \%)$ & $145(17.9 \%)$ \\
\hline medical doctors & & 10 & $22(62.9 \%)$ & $13(37.1 \%)$ & $35(4.3 \%)$ \\
\hline Meal Tray Delivery & $<0.0003$ & & & & \\
\hline yes & & 15 & $12(12.6 \%)$ & $83(87.4 \%)$ & $95(11.7 \%)$ \\
\hline no & & 61 & $217(30.3 \%)$ & $499(69.7 \%)$ & $716(88.3 \%)$ \\
\hline Patient into the Room & $<0,0001$ & & & & \\
\hline yes & & 62 & $227(30,7 \%)$ & $513(69,3 \%)$ & $740(91,2)$ \\
\hline no & & 15 & $2(2,8 \%)$ & $69(97,2 \%)$ & $71(8.8 \%)$ \\
\hline Housekeeping & $<0.0001$ & & & & \\
\hline yes, patient in the room & & 8 & $20(39.2 \%)$ & $31(60.8 \%)$ & $51(6.3 \%)$ \\
\hline no patient in the room & & 10 & $0(0.0 \%)$ & $49(100.0 \%)$ & $49(6.0 \%)$ \\
\hline no housekeeping & & 62 & 209 & 502 & 711 \\
\hline Type of the HCW path & $<0.0001$ & & & & \\
\hline Surreptitious entry & & 27 & $4(4.5 \%)$ & $85(95.5 \%)$ & $89(11.0 \%)$ \\
\hline no contact & & 43 & $40(32.0 \%)$ & $85(68.0 \%)$ & $125(15.4 \%)$ \\
\hline Contact with environment & & 36 & $73(21.7 \%)$ & $263(78.3 \%)$ & $336(41.4 \%)$ \\
\hline contact with patient & & 42 & $112(42.9 \%)$ & $149(57.1 \%)$ & $261(32.2 \%)$ \\
\hline Type of Care & $<0.000025$ & & & & \\
\hline non invasive & & 17 & $16(25.0 \%)$ & $48(75.0 \%)$ & $64(7.9 \%)$ \\
\hline invasive & & 13 & $38(43.7 \%)$ & $49(56.3 \%)$ & $87(33.2 \%)$ \\
\hline nursing & & 38 & $63(56.8 \%)$ & $48(43.2 \%)$ & $111(42.4 \%)$ \\
\hline not affected & & 58 & 112 & 437 & 549 \\
\hline
\end{tabular}

Table 2: Using of sanitizer

\begin{tabular}{|c|c|c|c|c|c|}
\hline \multicolumn{6}{|c|}{$\begin{array}{l}\text { Hand Disinfection } \\
\qquad \mathrm{N}=97\end{array}$} \\
\hline & $p^{*}$ & Before patient contact & After patient contact & $\begin{array}{c}\text { Before + After patient } \\
\text { contact }\end{array}$ & Total \\
\hline Type Of Care & 0.025 & & & & \\
\hline non invasive & & $4(7.7 \%)$ & $31(59.6 \%)$ & $17(32.7 \%)$ & $52(53.6 \%)$ \\
\hline invasive & & $2(6.7 \%)$ & $9(30.0 \%)$ & $19(63.3 \%)$ & $30(30.9 \%)$ \\
\hline nursing & & $3(20.0 \%)$ & $8(53.3 \%)$ & $4(26.7 \%)$ & $15(15.5 \%)$ \\
\hline Total & & $9(9.3 \%)$ & $48(49.5 \%)$ & $40(41.2 \%)$ & $97(100.0 \%)$ \\
\hline
\end{tabular}

Table 3: Hand disinfection and type of care.

with the meal tray, she put it on the table and exits the room without having hand disinfected (Supplemental Digital Content Video $\mathrm{N}^{\circ} 1$ ). In some paths (mainly for housekeeping: 49 of 71 or $69 \%$ ) the patient can be out of the room. When the patient is in the room, the HCWs especially the housekeepers had hand disinfection significantly more frequently than when there is no patient $(p<0.0001)$ (Table 2$)$. When the HCW is in contact with the environment, hand disinfection is significantly lower than when there is no contact at all $(p=0.02)$ (Table 2). Independently from the type of care, hand disinfection rate is always higher after than before contact with the patient (Table 3). When bedrooms were in isolation precaution for Clostridium difficile, 21 of 41 paths $(51.2 \%)$ were made with gloves but the conformity of gloves wearing to protocol is respected in only $7 / 41$ of paths $(17.5 \%)$ (Table 4). In all situations, wearing gloves significantly impaired hand disinfection $77 / 316(24.4 \%)$ versus $152 / 488(31.1 \%)(p=0.037)$ (Table $5)$. In situations in which gloves are not mandatory (standard, and airborne precaution situations), hand disinfection is significantly lower when gloves are worn 67/295 (22.7\%) versus 150/468 (32\%) $(p=0.0064)$ (Table 5). This is illustrated, where an assistant nurse enters with gloves in a room without isolation precaution, she takes the urinal of the patient and goes to the bathroom. She brings the urinal back to the patient and then exits the room with gloves and unidentified material of care (Supplemental Digital Content Supplemental Digital Content Video $\mathrm{N}^{\circ} 2$ ).

When bedrooms were in airborne isolation, the mask was appropriately worn in $353 / 389$ (90.7\%) (Table 6). This is illustrated, where a nurse enters without a mask into a room with airborne precaution. An assistant nurse gets into the room wearing a mask. She furtively gets out and reenters the room with another mask for the nurse (Supplemental Digital Content Video $\mathrm{N}^{\circ} 3$ ) [Supplementary A-C].

\section{Discussion}

In our study, for the first time healthcare workers practices 
Citation: Brouqui P, Boudjema S, Reynier P, Dufour JC, Florea O, et al. (2016) Hand Hygiene Analyzed by Video Recording. J Nurs Care 5: 338. doi:10.4172/2167-1168.1000338

Page 4 of 5

\begin{tabular}{|c|c|c|c|c|}
\hline \multicolumn{5}{|c|}{ Type of Isolation } \\
\hline & $p^{*}$ & $\begin{array}{l}\text { C. difficile isolation } \\
\qquad \mathrm{N}=41(\%)\end{array}$ & $\begin{array}{l}\text { Others or no isolation } \\
\qquad \mathrm{N}=770(\%)\end{array}$ & $\begin{array}{c}\text { Total } \\
(\mathrm{N}=811)\end{array}$ \\
\hline Wearing Gloves & 0.11 & & & \\
\hline YES & & $21(51.2 \%)$ & $295(38.7 \%)$ & $316(39.3 \%)$ \\
\hline NO & & $20(48.8 \%)$ & $468(61.3 \%)$ & $488(60.7 \%)$ \\
\hline Missing data & & 0 & 7 & 7 \\
\hline Conformity For Wearing Gloves & 0.37 & & & \\
\hline YES & & $7(17.5 \%)$ & $35(12.4 \%)$ & $42(13.0 \%)$ \\
\hline NO & & $33(82.5 \%)$ & $248(87.6 \%)$ & $281(87.0 \%)$ \\
\hline Missing data & & 1 & 19 & 20 \\
\hline Not affected & & 0 & 468 & 468 \\
\hline
\end{tabular}

Table 4: Conformity for wearing gloves in Clostridium difficile isolation precaution.

\begin{tabular}{|c|c|c|c|c|}
\hline \multicolumn{5}{|c|}{ Hand Disinfection } \\
\hline & $p^{*}$ & At least one time $\mathrm{N}=229$ & $\begin{array}{l}\text { Never } \\
\mathrm{N}=582\end{array}$ & Total $\mathrm{N}=811$ \\
\hline Wearing Gloves & 0.037 & & & \\
\hline YES & & $77(24.4 \%)$ & $239(75.6 \%)$ & $316(39.3 \%)$ \\
\hline NO & & $152(31.1 \%)$ & $336(68.9 \%)$ & $488(60.7 \%)$ \\
\hline Missing data & & 0 & 7 & 7 \\
\hline Wearing Gloves Only in no isolation & 0.0064 & At least one time $\mathrm{N}=217(28.4 \%)$ & Never $\mathrm{N}=546(71.6 \%)$ & Total $\mathrm{N}=763$ \\
\hline YES & & $67(22.7 \%)$ & $228(77.2 \%)$ & $295(38.7 \%)$ \\
\hline NO & & $150(32 \%)$ & $318(67.9 \%)$ & $468(61.3 \%)$ \\
\hline Missing data & & 0 & 7 & 7 \\
\hline Wearing Gloves in C.D isolation & & 0 & 0 & 41 \\
\hline${ }^{*}$ Chi test & & & & \\
\hline
\end{tabular}

Table 5: Gloves wearing and hand disinfection.

\begin{tabular}{|c|c|c|c|c|c|}
\hline \multicolumn{6}{|c|}{ Type of Isolation } \\
\hline & $p^{*}$ & Number of HCWS & $\begin{array}{c}\text { Other isolations } \\
N=423(\%)\end{array}$ & $\begin{array}{l}\text { Airborne isolation } \\
\quad \mathrm{N}=388(\%)\end{array}$ & $\begin{array}{c}\text { Total } \\
(\mathrm{N}=811)\end{array}$ \\
\hline Wearing Mask & $<0.0001$ & $\begin{array}{c}\mathrm{n} \\
(\% \text { column })\end{array}$ & $\begin{array}{l}\mathrm{n}(\% \text { column }) \\
(\% \text { row })\end{array}$ & $\begin{array}{l}\mathrm{n}(\% \text { column }) \\
(\% \text { row })\end{array}$ & \\
\hline YES & & 42 & $\begin{array}{c}36(8.5 \%) \\
(9.3 \%)\end{array}$ & $\begin{array}{c}353(91.0 \%) \\
(90.7 \%)\end{array}$ & $389(48.0 \%)$ \\
\hline NO & & 53 & $\begin{array}{c}387(91.5 \%) \\
(91.7 \%)\end{array}$ & $\begin{array}{c}35(9.0 \%) \\
(8.3 \%)\end{array}$ & $422(52.0 \%)$ \\
\hline
\end{tabular}

Table 6: Wearing mask and type of isolation.

were observed in routine care by video recording. Our results show that hand disinfection rate is very low and much lower than other published studies [4] but consistent with that of Armellino who reports $6.5 \%$ compliance at the beginning of their study [12,13]. Unlike observational studies using WHO protocol $[1,6]$, our results and that of Armellino were much lesser influenced by the "Hawthorn effect" $[7,12,18]$. Blind analysis and comparison by two different observers likely attenuate a possible interpretation bias. Videotapes have been archived and can be further analyzed if needed which is one of the main advantages of video recording. It is important to notice that remote video recording is time consuming, and that these data should be interpreted with care as they reflect the situation in one care unit in a short duration of observation.

In our study, the hand hygiene adhesion is disturbed in two situations, namely gloves wearing and meal tray delivery. As reported in many studies gloves are worn in situation were not indicated and vice versa [19]. The hand disinfection compliance rate in our study as well as in other reported study was significantly reduced when gloves are worn [20]. Gloves wearing create confusion among HCWs. Nonsterile gloves are mostly used as a protection towards patients' body fluids during nursing by assistant nurses. They wear glove after room entry and hand disinfection prior to gloves wearing in not performed. Among HCW's explanation is the difficulty to wear gloves upon wet hands, and time waste. In Clostridium difficile isolation procedure, gloves must be worn before room entrance and removed into the room before exit [15]. The complexity and the diversity of protocols and the fact that these protocols dictated by infection control team may explain that they are poorly observed.

Hand hygiene is worst in situation where the meal tray is given to patients. In our experience $87 \%$ of HCWs that deliver the meal never use hand disinfection. In one recently published study in an emergency medical service hand sanitizing were observed in $19 \%$ of cases only before meal delivery [21-26]. This discrepancy may be due to the fact that hand hygiene outside the room was not evaluated in our study considering that only hand hygiene in the room at patient's bedside was appropriated. Caring the tray does not facilitate hand disinfection 
taking into account the fact that time spent for delivery is short due to meal preservation conditions. However if hands are not disinfected before meal delivery it could be done just after, and before exit from the room.

Compliance with mask wearing is very high (90.7\%). Airborne isolation is mainly linked to tuberculosis which appears as a specific contagious disease and one may suggest that this difference in behaviors may be related to risk perception of acquiring the disease and transmitting to close contact. This risk appears as most visible that hand transmit nosocomial infection. In infectious disease ward very few if no patient acquire infection in the time of care (mean length of stay $<8$ days), which may contribute to the thinking that in infectious disease ward, HCWs are, not involved in transmission. Our study has some limitations. The observations were done in only one room. Video recording was performed only within the room making hidden all events outside the room. Although very efficient $[12,13]$, we do not believe that remote video analysis is a tool for improving and maintaining hand hygiene compliance as it poses numerous privacy questions, is time consuming and very expensive. However remote video analysis is a performing tool in research to study health care workers behavior and understanding issues that might explain poor compliance.

In conclusion, as used in sport, video recording is a tool that can be useful for studding performance in health care practices allowing to identified yet unidentified situations. The lack of adhesion to hand hygiene is multifaceted. The analysis of videotapes allows observing the real life with minor bias. While wearing gloves disturb the sequence of care gestures, hand hygiene before meal tray delivery is questionable. More simple hand hygiene protocols including gloves wearing, focusing on high-risk transmission practices (ex: during nursing and invasive care) and adapted to health care workers behavior would improve the compliance of hand hygiene and adhesion to isolation protocols.

\section{Acknowledgement}

Authors want to thank Alberto Soto Aladro and Isabelle Desquerre (engineers) for implication in the MediHandTrace ${ }^{\circledR}$ data collection and all the infectious disease staff including, nurses, assistant nurses, housekeepers and physicians who participate to the study. We wanted to thank the MediHandTrace ${ }^{\circledR}$ consortium for providing the video camera and computer for data collection. The authors also thank Dr JC Lagier for participation in some video analysis.

\section{References}

1. Marra AR, Faria Moura D, Tavares Paes A, Pavao Dos Santos OF, et al. (2010) Measuring rates of hand hygiene adherence in the intensive care setting: a comparative study of direct observation, product usage, and electronic counting devices. Infection Control and Hospital Epidemiology 31: 796-801.

2. Boyce JM, Pittet D (2002) Guideline for hand hygiene in health-care settings: recommendations of the healthcare infection control practices advisory committee and the HICPAC/SHEA/APIC/IDSA hand hygiene task force. Infection Control and hospital Epidemiology 23: S3-S41.

3. Pittet D, Allegranzi B, Boyce JM (2009) The World Health Organization guidelines on hand hygiene in health care and their consensus recommendations. Infection Control and Hospital Epidemiology. World Health Organization World Alliance for Patient Safety Fist Global Patient Safety Challenge Core Group of Experts 30: 611-622

4. Erasmus V, Daha TJ, Brug H, Richardus JH, Behrendt MD, et al. (2010) Systematic review of studies on compliance with hand hygiene guidelines in hospital care. Infect Control Hosp Epidemiol 31: 283-294.

5. Sax H, Allegranzi B, Uçkay I, Larson E, Boyce J, et al. (2007) 'My five moments for hand hygiene': a user-centred design approach to understand, train, monitor and report hand hygiene. J Hosp Infect 67: 9-21.

6. Haas JP, Larson EL (2007) Measurement of compliance with hand hygiene. J Hosp Infect 66: 6-14.

7. Adair JG (1984) The Hawthorne effect: a reconsideration of the methodological artifact. Journal of Applied Psychology 69: 334-345.
8. Eckmanns T, Bessert J, Behnke M, Gastmeier P, Ruden H (2006) Compliance with antiseptic hand rub use in intensive care units: the Hawthorne effect. Infect Control Hosp Epidemiol 27: 931-934.

9. Carson F (2008) Utilizing video to facilitate reflective practice: developing sports coaches. International Journal of Sports Science and Coaching 3: 381-390.

10. Smeeton SJ, Hibbert JR, Stevenson K, Cumming J, Williams AM (2013) Can imaginary facilitate improvements in anticipation behavior? Psychology of Sport and Exercise 14: 200-210.

11. Robinovitch SN, Feldman F, Yang Y, Schonnop R, Leung PM, et al. (2013) Video capture of the circumstances of falls in elderly people residing in longterm care: an observational study. Lancet 381: 47-54.

12. Armellino D, Hussain E, Schilling ME, Senicola W, Eichorn A, et al. (2012) Using high technology to enforce low-technology safety measures: the use of third party remote video auditing and real-time feedback in healthcare. Clinical Infectious Diseases 54: 1-7.

13. Armellino D, Trivedi M, Law I, Singh N, Schilling ME, et al. (2013) Replicating changes in hand hygiene in a surgical intensive care unit with remote video auditing and feedback. Am J Infect Control 41: 925-927.

14. Cohen SH, Gerding DN, Johnson S, Kelly CP, Loo VG, et al. (2010) Clinical practice guidelines for Clostridium difficile infection in adults: 2010 Update by the Society for Healthcare Epidemiology of America (SHEA) and the Infectious Diseases Society of America (IDSA). Infection Control and Hospital Epidemiology 31: 431-455.

15. Siegel JD, Rhinehart E, Jackson M, Chiarello L (2007) Healthcare Infection Control Practices Advisory Committee. Guideline for isolation precautions: preventing transmission of infectious agents in healthcare settings. American Journal of Infection Control.

16. Whitby M, McLaws ML, Ross MW (2006) Why healthcare workers don't wash their hands: a behavioral explanation. Infect Control Hosp Epidemiol 27: 484 492.

17. Boudjema S, Dufour JC, Soto Aladro A, Desquerres I, Brouqui P (2014) MediHandTrace $\AA$ : a tool for measuring and understanding hand hygiene adherence. clinical microbiology and infection: The Official Publication of the European Society of Clinical Microbiology and Infectious Diseases 20: 22-28.

18. Srigley JA, Furness CD, Baker GR, Gardam M (2014) Quantification of the Hawthorne effect in hand hygiene compliance monitoring using an electronic monitoring system: a retrospective cohort study. BMJ Quality and Safety 23: 974-980.

19. Girou E, Chai SH, Oppein F, Legrand P, Ducellier D, et al. (2004) Misuse of gloves: the foundation for poor compliance with hand hygiene and potential for microbial transmission? J Hosp Infect 57: 162-169.

20. Fuller C, Savage J, Besser S, Hayward A, Cookson B, et al. (2011) "The dirty hand in the latex glove": a study of hand hygiene compliance when gloves are worn. Infect Control Hosp Epidemiol 32: 1194-1199.

21. Ho JD, Ansari RK2, Page D3 (2014) Hand sanitization rates in an urban emergency medical services system. J Emerg Med 47: 163-168.

22. Biran A, Schmidt WP, Wright R, Jones T, Seshadri M, et al. (2009) The effect of a soap promotion and hygiene education campaign on handwashing behaviour in rural India: a cluster randomised trial. Tropical Medicine \& International Health 14: 1303-14.

23. Knoll M, Lautenschlaeger C, Borneff-Lipp M (2010) The impact of workload on hygiene compliance in nursing. Br J Nurs 19: S18-22.

24. McLaughlin AC, Walsh F (2012) Self-reported reasons for hand hygiene in 3 groups of health care workers. Am J Infect Control 40: 653-658.

25. Pittet D, Hugonnet S, Harbarth S, Mourouga P, Sauvan V, et al. (2000) Effectiveness of a hospital-wide programme to improve compliance with hand hygiene. Infection Control Programme. Lancet 356: 1307-1312.

26. Whitby M, Pessoa-Silva CL, McLaws ML, Allegranzi B, Sax H, et al. (2007) Behavioural considerations for hand hygiene practices: the basic building blocks. J Hosp Infect 65: 1-8. 